\title{
ANALISIS SISTEM PELAYANAN KERETA API DI STASIUN SEMARANG TAWANG MENGGUNAKAN PROSES BAYESIAN
}

\author{
Lifana Nugrae ni ${ }^{1}$, Sugito ${ }^{2}$, Dwi Ispriyanti ${ }^{3}$ \\ 1, 2, 3 Departemen Statistika, Fakultas Sains dan Matematika, Universitas Diponegoro \\ lifananugraeni@students.undip.ac.id
}

\begin{abstract}
ABSTRAK
Along with the times, transportation has progressed. Regarding the means of transportation, one of the phenomenon that is easily encountered in everyday life is the queue at public transportation facilities. One of the queues that occurred at public transportation facilities is the train queue at Semarang Tawang Station. The number of trains that passes the station can cause the train service at the station busy. This study aims to see whether the train service system of Semarang Tawang Station is good or not. This can be consider by the queues method, determining the distribution of arrival patterns and service patterns to obtain a queues system model and a system performance standard. In this study, the distribution of arrival patterns and service patterns are determined by calculating the posterior distribution using the Bayesian method. The bayesian method was chosen because it is able to combine the sample distribution in the current study with the previous information for the same cases. The prior distribution and the likelihood function are the elements needed to obtain the posterior distribution. The distribution of arrival patterns and service patterns obtained from previous information follows the Poisson distribution. Based on the calculation of the posterior distribution, the result shows that the distribution of the arrival pattern is a discrete uniform distribution and the distribution of the service pattern is a Poisson distribution. The result shows that the train service system at Semarang Tawang Station has a model (Uniform Discrete / Gamma / 7: GD / / ) and has good service based on the performance values obtained.
\end{abstract}

Keywords: train, Semarang Tawang Station, bayesian, posterior distribution, the queue model, performance measure of queue system, discrete uniform, gamma.

\section{PENDAHULUAN}

Seiring dengan perkembangan zaman, bidang transportasi pun mengalami kemajuan. Akses transportasi semakin mudah didapatkan, segala kegiatan berjarak jauh juga dapat ditempuh dengan mudah. Berkaitan dengan alat transoprtasi, salah satu fenomena yang mudah dijumpai dalam kehidupan sehari-hari adalah antrean pada fasilitas trasnportasi umum. Menurut Kakiay (2004), situasi menunggu merupakan bagian dari keadaan yang terjadi dalam rangkaian kegiatan operasional yang bersifat random dalam suatu fasilitas pelayanan.

Salah satu fenomena antrean yang terjadi pada fasilitas pelayanan umum terlihat pada antrean kereta api di Stasiun Semarang Tawang. Stasiun Semarang Tawang merupakan salah satu stasiun kelas besar tipe A yang terdiri dari 7 jalur pelayanan dan terletak di Semarang Utara, Kota Semarang. Kereta dengan jumlah banyak yang melintas di stasiun, terdapat perubahan jadwal pemberangkatan kereta, kejadian di luar dugaan seperti kereta kehabisan bahan bakar atau terjadi kecelakaan menyebabkan terjadinya antrean kereta, dan hal tersebut diduga menyebabkan penumpukan kereta pada stasiun. Penumpukan kereta dapat 
menyebabkan sistem pelayanan di stasiun sibuk, sehingga peneliti ingin mengetahui apakah sistem pelayanan di Stasiun Semarang Tawang sudah baik atau belum dengan adanya penumpukan kereta tersebut. Oleh karena itu, teori antrean dapat diterapkan untuk mengurangi masalah yang terjadi pada antrean kereta.

Menurut Armero dan Bayarri (1995), dalam metode antrean didapatkan distribusi yang memenuhi tidak hanya satu distribusi melainkan terdapat beberapa ranking, sehingga metode bayesian dapat mengkombinasikan distribusi yang memungkinkan dengan pertimbangan hasil pada penelitian sebelumnya. Oleh karena peneliti ingin mengkombinasikan distribusi yang memungkinkan dengan distribusi penelitian sebelumnya, maka peneliti terdorong untuk mencari distribusi kedatangan dan distribusi pelayanannya dengan menggunakan distribusi posterior melalui metode bayesian. Metode bayesian perlu digunakan karena dalam berjalannya waktu antara penelitian sebelumnya hingga penelitian sekarang pasti terdapat perubahan atau tambahan informasi, sehingga perlu dikombinasikan antara penelitian sekarang dengan penelitian sebelumnya.

Perhitungan distribusi posterior sendiri membutuhkan distribusi prior dan fungsi likelihood. Pertama distribusi prior, penerapan teori antrean di Stasiun Semarang Tawang pernah dilakukan pada penelitian sebelumnya (Nursihan, 2014). Penelitian tersebut digunakan sebagai informasi prior dari penelitian sekarang, dengan alasan karena objeknya sama yaitu mengamati pelayanan di Stasiun Semarang Tawang, serta telah dilakukan sebelumnya. Penelitian sebelumnya (Nursihan, 2014) termasuk dalam distribusi prior non informatif karena pada penelitian tersebut tidak diketahui informasi lebih lanjut terkait parameter dari distribusi kedatangan dan pelayanannya. Salah satu metode untuk mencari pendekatan distribusi prior non informatif adalah metode Jeffrey (Berger, 1980). Kedua, selain distribusi prior, dalam perhitungan distribusi posterior dibutuhkan juga fungsi likelihood. Menurut Cassela dan Berger (2001), fungsi likelihood adalah informasi yang diperoleh mengenai fungsi kepekatan peluang dari data sampel. Data sampel pada penelitian ini, akan diambil secara langsung dengan melakukan pengamatan data kedatangan dan pemberangkatan kereta api di Stasiun Semarang Tawang.

Penulis mengharapkan pada penelitian ini dapat ditentukan model sistem antrean dan ukuran kinerja sistem berdasarkan distribusi posterior yang didapatkan. Distribusi posterior dari pola kedatangan dan pola pelayanan kereta api perlu didapatkan menggunakan metode bayesian karena seiring berjalannya waktu terdapat perubahan atau tambahan informasi, sehingga perlu dikombinasikan antara penelitian sekarang dengan penelitian sebelumnya.

\section{TINJAUAN PUSTAKA}

\subsection{Gambaran Umum Stasiun Semarang Tawang}

Stasiun Semarang Tawang (SMT) adalah stasiun kelas besar tipe A di Tanjung Mas, Semarang Utara, Semarang, yang merupakan stasiun terbesar yang berada dalam pengelolaan PT Kereta Api Indonesia (Persero) Daerah Operasi 4 Semarang. Stasiun ini memiliki delapan jalur kereta api, tetapi yang aktif untuk digunakan terdapat 7 jalur kereta.

\subsection{Deskripsi Antrean}

Menurut Kakiay (2004), antrean adalah suatu garis tunggu dari sejumlah pelanggan yang memerlukan pelayanan dari satu atau lebih fasilitas pelayanan. Proses antrean (queueing process) adalah suatu proses yang berhubungan dengan kedatangan pelanggan pada suatu fasilitas pelayanan, menunggu dalam baris antrean jika belum dapat dilayani, dilayani dan akhirnya meninggalkan fasilitas tersebut sesudah dilayani. 


\subsection{Faktor Sistem Antrean}

Menurut Kakiay (2004) ada beberapa faktor penting yang terkait erat dengan sistem antrean. Faktor-faktor yang berpengaruh terhadap barisan antrean dan pelayanannya adalah Distribusi Kedatangan (Pola Kedatangan), Distribusi Waktu Pelayanan (Pola Pelayanan), Fasilitas Pelayanan, Disiplin Pelayanan, Ukuran dalam Antrean, dan Sumber Pemanggilan.

\subsection{Struktur Dasar Sistem Antrean}

Menurut Subagyo et al. (1992), ada empat model struktur antrean dasar yang umum terjadi dalam seluruh sistem antrean, antara lain Satu Antrean Satu Pelayanan (Single Channel-Single Phase), Satu Antrean, Beberapa Pelayanan Seri (Single ChannelMultiphase), Satu Antrean Beberapa Pelayanan Paralel (Multichannel-Single Phase), dan Beberapa Antrean Beberapa Pelayanan Paralel (Multichannel-Multiphase).

\subsection{Notasi Kendall}

Notasi yang sering dipergunakan karena notasi tersebut merupakan alat yang efisien untuk mengidentifikasi tidak hanya model-model antrean, tetapi juga asumsi-asumsi yang harus dipenuhi (Subagyo et al, 1992). Format umum model:

$$
(a / b / c):(d / e / f)
$$

dimana:

$a$ : Distribusi kedatangan (arrival distribution).

$b$ : Distribusi waktu pelayanan (service time distribution).

$c$ : Jumlah tempat pelayanan (dengan $c=1,2,3, \ldots \infty$ ).

$d$ : Disiplin pelayanan misalkan FCFS, LCFS, SIRO, PRI.

$e$ : Jumlah maksimum pelanggan yang diizinkan dalam sistem.

$f$ : Sumber pemanggilan.

\subsection{Ukuran Steady State}

Menurut Taha (1996), steady state merupakan kondisi sewaktu sifat-sifat sistem tidak berubah dengan berjalannya waktu (konstan), $\rho$ didefinisikan sebagai perbandingan antara rata-rata pelanggan yang datang $(\lambda)$ dengan rata-rata pelanggan yang telah dilayani per satuan waktu $(\mu)$, atau dapat dituliskan sebagai berikut:

$$
\rho=\frac{\lambda}{c \mu}
$$

dengan c merupakan jumlah fasilitas pelayanan yang tersedia. Jika $\rho<1$ maka dapat diartikan memenuhi kondisi steady-state atau kondisi ketika sifat-sifat suatu sistem tak berubah dengan berjalannya waktu (konstan).

\subsection{Uji Kolmogorov Smirnov}

Menurut Daniel (1989), asumsi dalam uji Kolmogorov Smirnov adalah data terdiri atas hasil pengamatan bebas $\mathrm{Y}_{1}, \mathrm{Y}_{2}, \ldots, \mathrm{Y}_{\mathrm{i}}$, yang merupakan sebuah sampel acak berukuran $\mathrm{i}$ dari suatu fungsi distribusi yang belum diketahui dan dinyatakan dengan $\mathrm{F}_{0}(\mathrm{y})$.

Adapun langkah-langkah uji Kolmogorov Smirnov sebagai berikut:

a. Menentukan Hipotesis

$\mathrm{H}_{0}$ : Distribusi sampel mengikuti distribusi yang ditetapkan

$\mathrm{H}_{1}$ : Distribusi sampel tidak mengikuti distribusi yang ditetapkan

b. Menentukan Taraf Signifikansi

Taraf signifikansi yang digunakan adalah $\alpha=5 \%$

c. Statistik Uji

$$
\mathrm{D}=\underset{1 \leq i \leq r}{\operatorname{maximum}}\left\{\operatorname{maximum}\left[\left|S\left(y_{i}\right)-F_{0}\left(y_{i}\right)\right| \cdot\left|S\left(y_{i-1}\right)-F_{0}\left(y_{i}\right)\right|\right]\right\}
$$


dengan:

$S\left(y_{i}\right)$ : fungsi peluang kumulatif yang dihitung dari data sampel

$F_{0}\left(y_{i}\right)$ : fungsi distribusi yang dihipotes iskan (fungsi peluang kumulatif)

d. Kriteria Uji

Tolak $\mathrm{H}_{0}$ jika pada taraf signifikansi $\alpha$ jika nilai $\mathrm{D} \geq$ nilai Dtabel $(1-\alpha)$ atau jika nilai sig $<$ nilai $\alpha . \mathrm{D}_{\text {tabel }}(\alpha)$ adalah nilai kritis yang diperoleh dari tabel KolmogorovSmirnov.

\subsection{Model Antrean (G/G/c):(GD/ $\infty / \infty)$}

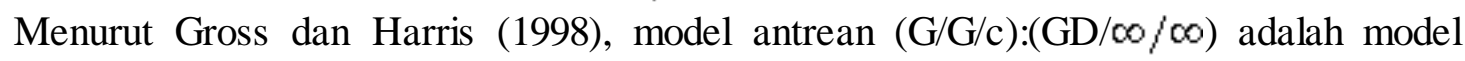
antrean dengan pola kedatangan berdistribusi umum (general) dan pola pelayanan berdistribusi umum (general) dengan jumlah fasilitas pelayanan sebanyak $c, c=1,2,3, \ldots$. Disiplin antrean yang digunakan pada model ini adalah umum yaitu FCFS (First Come First Serve), kapasitas maksimum yang diperbolehkan dalam sistem adalah tak hingga, dan memiliki sumber pemanggilan tak hingga. Rumus untuk mencari ukuran-ukuran kinerja pada model $(\mathrm{G} / \mathrm{G} / \mathrm{c}):(\mathrm{GD} / \infty / \infty)$ adalah sebagai berikut :

$$
\begin{aligned}
& L_{q}=\frac{r^{c} \rho P_{o}}{c !(1-\rho)^{2}}\left(\frac{\mu^{2}\left(\frac{1}{\mu^{2}}\right)^{2}+\lambda^{2}\left(\frac{1}{\lambda^{2}}\right)^{2}}{2}\right) \\
& L_{s}=L_{q}+\rho \quad W_{q}=\frac{L_{q}}{\lambda} \quad W_{s}=W_{q}+\frac{1}{\mu}
\end{aligned}
$$

\subsection{Distribusi Uniform Diskrit}

Menurut Bain dan Engelhardt (1992), sebuah variabel random diskrit Y berdistribusi uniform diskrit untuk $1,2, \ldots, N$ jika memiliki fungsi kepadatan peluang sebagai berikut :

$$
f(y)=\frac{1}{\mathrm{~N}}, \quad \mathrm{y}=1,2, \ldots, N
$$

Notasi untuk keadaan tersebut yaitu $: Y \sim$ Uniform Diskrit (N)

\subsection{Distribusi Gamma}

Menurut Bain dan Engelhardt (1992), sebuah variabel random diskrit Y berdistribusi gamma dengan parameter $k>0$ dan $\theta>0$ jika memiliki fungsi kepadatan peluang sebagai berikut :

$$
f(y ; \theta, \mathrm{k})=\frac{1}{\theta^{k} \Gamma(k)} y^{k-1} e^{k / \theta} \quad, y>0
$$

Notasi untuk keadaan tersebut yaitu $: Y \sim \operatorname{Gamma}(\theta, \mathrm{k})$

\subsection{Metode Bayesian}

Pendekatan Bayes dalam mengestimasi estimator dari parameter menggabungkan informasi dari sampel dengan informasi lain telah tersedia sebelumnya (Soejoeti dan Soebanar, 1988).

\subsubsection{Distribusi Prior}

Menurut Soejoti dan Soebanar (1988), distribusi prior adalah distribusi awal yang harus ditentukan terlebih dahulu sebelum merumuskan distribusi posteriornya, dan didapat dari pengalaman pada masa lalu. Menurut Box dan Tiao (1973), berdasarkan penentuan masing-masing parameter terbagi menjadi informasi prior informatif dan informasi prior noninformatif. Menurut Berger (1980), salah satu bentuk pendekatan dari prior non-informatif adalah dengan menggunakan metode Jeffrey. Metode ini menyatakan bahwa distribusi prior $f(\lambda)$ merupakan akar kuadrat dari informasi Fisher yang dinyatakan dalam: 


$$
\begin{aligned}
& f(\lambda)=[I(\lambda)]^{1 / 2} \\
& I(\lambda)=-E_{0}\left[\frac{\partial^{2} \ln L(\lambda)}{\partial^{2} \lambda}\right]
\end{aligned}
$$

dengan $f(\lambda)$ : Distribusi prior

$E_{0} \quad$ : Nilai harapan

$I(\lambda)$ : Informasi Fisher

\subsubsection{Fungsi Likelihood}

Menurut Bain dan Engelhardt (1992), fungsi likelihood adalah fungsi densitas bersama dari $n$ variabel random $T_{1}, T_{2}, \ldots, T_{n}$ dan dinyatakan dalam bentuk $f\left(t_{1}, t_{2}, \ldots, t_{n} ; \lambda\right)$.

$$
\begin{aligned}
L(\lambda) & =f\left(t_{1} \mid \lambda\right) f\left(t_{2} \mid \lambda\right) \ldots f\left(t_{n} \mid \lambda\right) \\
& =\prod_{i=1}^{n} f\left(t_{i} \mid \lambda\right)
\end{aligned}
$$

\subsubsection{Distribusi Posterior}

Menurut Box dan Tiao (1973), distribusi posterior adalah penggabungan distribusi sampel dan distribusi prior.

distribusi posterior $\propto$ likelihood $x$ distribusi prior

$f(\lambda \mid t)=L(\lambda) \cdot f(\lambda)$

dimana $L(\lambda)$ merupakan fungsi likelihood dan $f(\lambda)$ merupakan distribusi prior.

\section{METODOLOGI PENELITIAN}

\subsection{Sumber Data dan Variabel Penelitian}

Data yang digunakan dalam penelitian ini merupakan data primer yang diambil pada tanggal 10 Januari 2020 sampai tanggal 16 Januari 2020 mulai pukul 12.30 WIB sampai pukul 22.30 WIB di Stasiun Semarang Tawang. Variabel penelitiannya adalah data jumlah kedatangan dan jumlah pelayanan kereta api yang melintas di jalur Stasiun Semarang Tawang.

\subsection{Langkah-langkah Analisis}

Langkah pertama dalam penelitian ini adalah melakukan penyusunan program GUI $R$ selanjutnya dilakukan pemodelan menggunakan program yang telah disusun, dengan langkah: sebagai berikut:

a. Memeriksa data yang sudah didapat untuk pemenuhan steady-state.

b. Melakukan uji kecocokan distribusi poisson untuk mendapatkan distribusi yang paling tepat.

c. Setelah diketahui distribusinya, maka distribusi tersebut digunakan sebagai fungsi likelihood dalam menghitung distribusi posterior.

d. Kemudian menghitung distribusi posterior dengan distribusi priornya adalah data antrean kereta api menggunakan penelitian sebelumnya.

e. Setelah dari distribusi posterior, dapat ditentukan model antrean yang sesuai dengan distribusi posteriornya.

f. Kemudian dapat dihitung dan dianalisis ukuran kinerja dari sistem antrean.

g. Membuat hasil dan pembahasan yang diperoleh suatu model yang optimal.

h. Mengambil keputusan mengenai pelayanan kereta di Stasiun Tawang Semarang secara keseluruhan. 


\section{HASIL DAN PEMBAHASAN}

\subsection{Gambaran Umum Sistem Antrean Ke reta Api di Stasiun Semarang Tawang}

Stasiun Semarang Tawang terdapat dua arah jalur, jalur barat adalah jalur yang dimana kereta yang datang dan berangkat dari dan ke arah barat, dengan stasiun pertama yang berada di jalur barat adalah Stasiun Poncol. Sedangkan jalur timur adalah jalur yang dimana kereta yang datang dan berangkat dari dan ke arah timur, dengan stasiun pertama yang berada di jalur barat adalah Stasiun Ngrombo. Sistem antrean kereta api di Stasiun Semarang Tawang adalah sebagai berikut:

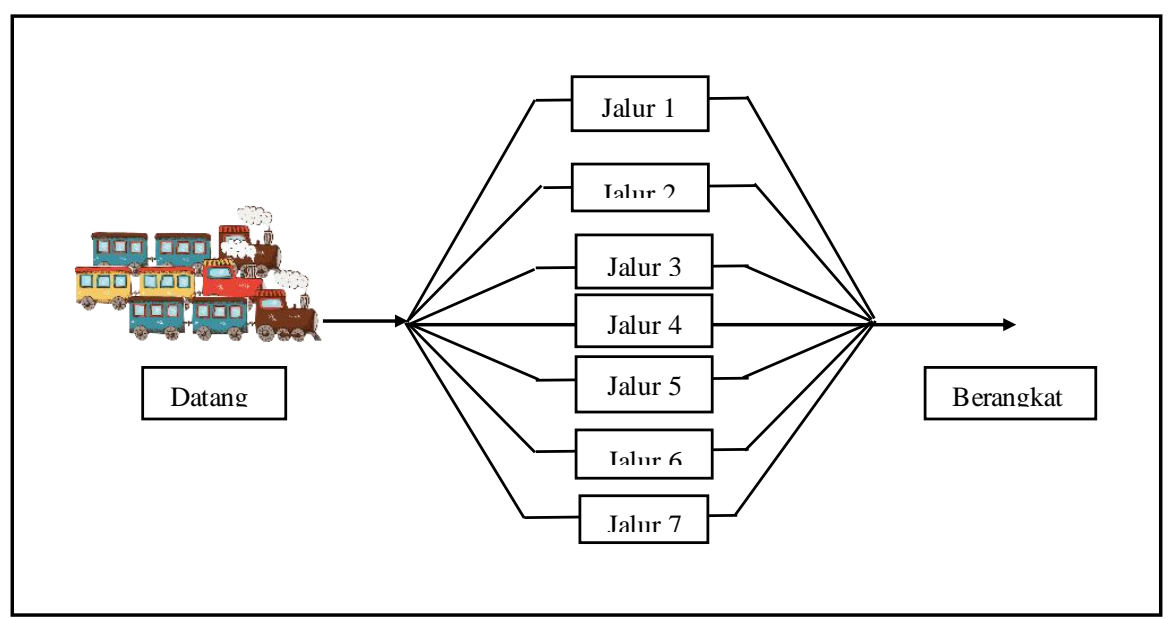

Gambar 1. Sistem Antrean Stasiun Semarang Tawang

\subsection{Analisis Steady State}

Kondisi steady state harus terpenuhi sehingga dapat diketahui bahwa jumlah rata-rata pelanggan yang datang lebih kecil dari rata-rata laju pelayanan agar sistem pelayanan mencapai keadaan yang stabil. Berikut hasil perhitungan nilai $\rho$ :

Tabel 1. Analis is Steady State

\begin{tabular}{cccc}
\hline $\mathrm{c}$ & $\lambda$ & $\mu$ & $\rho=\frac{\lambda}{c \mu}$ \\
\hline 7 & 6,17143 & 6,17143 & 0,14286 \\
\hline
\end{tabular}

Dari Tabel 1 diatas dapat diketahui bahwa nilai tingkat kegunaan fasilitas pelayanan di Stasiun Semarang Tawang sudah kurang dari satu. Sehingga dapat disimpulkan bahwa sistem antrean di Stasiun Semarang Tawang sudah steady-state.

\subsection{Uji Kecocokan Distribusi}

Pada uji kecocokan distribusi akan diketahui apakah data jumlah kereta api yang datang dan jumlah kereta api yang dilayani berdistribusi poisson atau tidak, apabila tidak akan dicari hingga ditemukan distribusinya.

\subsubsection{Uji Distribusi Data Jumlah Kedatangan}

Dilakukan pengujian distribusi poisson pada data jumlah kedatangan setiap 120 menit yaitu dengan pengujian hipotesis berikut:

Hipotesis: $\mathrm{H}_{0}$ : Data jumlah kedatangan kereta api berdistribusi poisson 
$\mathrm{H}_{1}$ : Data jumlah kedatangan kereta api tidak berdistribusi poisson

Jika diambil $\alpha=5 \%$, dan nilai kritis yaitu Dtabel $=0,224$. Nilai statistik uji yang diperoleh adalah $D=0,24712$ dengan $p$ value $=0,02783$. Daerah penolakan $\mathrm{H}_{0}$ adalah Dhitung > 0,224 , karena 0,24712 berada di daerah penolakan $\mathrm{H}_{0}$ maka $\mathrm{H}_{0}$ ditolak. Sehingga dengan taraf signifikansi $\alpha=5 \%$ dapat disimpulkan bahwa data jumlah kedatangan kereta tidak berdistribusi poisson.

Karena data jumlah kereta api yang datang tidak berdistribusi poisson, maka perlu dilakukan pengujian kecocokan distribusi kembali hingga didapatkan distribusinya, berikut pengujian hipotesisnya:

Hipotesis: $\mathrm{H}_{0}$ : Data jumlah kedatangan kereta api berdistribusi uniform diskrit

$\mathrm{H}_{1}$ : Data jumlah kedatangan kereta api tidak berdistribusi uniform diskrit

Jika diambil $\alpha=5 \%$, dan nilai kritis yaitu Dtabel $=0,224$. Nilai statistik uji yang diperoleh adalah $D=0,1619$ dengan $p$ value $=0,22425$. Daerah penolakan $\mathrm{H}_{0}$ adalah Dhitung > 0,224 , karena 0,1619 berada di daerah penerimaan $\mathrm{H}_{0}$ maka $\mathrm{H}_{0}$ diterima. Sehingga dengan taraf signifikansi $\alpha=5 \%$ dapat disimpulkan bahwa data jumlah kedatangan kereta berdistribusi uniform diskrit.

\subsubsection{Uji Distribusi Data Jumlah Pelayanan}

Dilakukan pengujian distribusi poisson pada data jumlah pelayanan setiap 120 menit yaitu dengan pengujian hipotesis berikut:

Hipotesis: $\mathrm{H}_{0}$ : Data jumlah pelayanan kereta api berdistribusi poisson

$\mathrm{H}_{1}$ : Data jumlah pelayanan kereta api tidak berdistribusi poisson

Jika diambil $\alpha=5 \%$, dan nilai kritis yaitu Dtabel $=0,224$. Nilai statistik uji yang diperoleh adalah $D=0,20047$ dengan $p$ value $=0,12$. Daerah penolakan $\mathrm{H}_{0}$ adalah Dhitung $>0,224$, karena 0,20047 berada di daerah penerimaan $\mathrm{H}_{0}$ maka $\mathrm{H}_{0}$ diterima. Sehingga dengan taraf signifikansi $\alpha=5 \%$ dapat disimpulkan bahwa data jumlah pelayanan kereta berdistribusi poisson.

\subsection{Distribusi Posterior}

\subsubsection{Fungsi Likelihood}

\subsubsection{Fungsi Likelihood untuk Data Jumlah Kedatangan}

Karena data jumlah kedatangan berdistribusi uniform diskrit, maka fungsi likelihoodnya sebagai berikut:

$$
L(\lambda)=\prod_{i=1}^{n} f\left(y_{i}\right)=\prod_{i=1}^{n} \frac{1}{\lambda}=\left(\frac{1}{\lambda}\right)^{n}
$$

\subsubsection{Fungsi Likelihood untuk Data Jumlah Pelayanan}

Karena data jumlah pelayanan berdistribusi poisson, maka fungsi likelihood-nya sebagai berikut:

$$
L(\lambda)=\prod_{i=1}^{n} f\left(y_{i}\right)=\prod_{i=1}^{n} \frac{e^{-\lambda} \lambda^{y_{i}}}{x_{i} !}=\frac{e^{-\lambda n} \lambda^{\sum_{i=1}^{n} y_{i}}}{\prod_{i=1}^{n} y_{i} !}
$$

\subsubsection{Distribusi Prior}

\subsubsection{Distribusi Prior Data Jumlah Kedatangan}

Berdasarkan penelitian sebelumnya, data jumlah kedatangan berdistribusi poisson, sehingga perhitungan distribusi priornya adalah:

$$
I(\lambda)=-E\left[\frac{\partial^{2} \log f(y ; \lambda)}{\partial \lambda^{2}}\right] \quad f(\lambda)=\sqrt{I(\lambda)}
$$




$$
\begin{aligned}
& =-E\left[-\frac{y}{\lambda^{2}}\right] \quad=\frac{1}{\sqrt{\lambda}} \\
& =\frac{1}{\lambda^{2}} E[y] \quad=\lambda^{-\frac{1}{2}} \\
& =\frac{1}{\lambda^{2}} \lambda \quad \propto \lambda^{-\frac{1}{2}} \\
& =\frac{1}{\lambda}
\end{aligned}
$$

\subsubsection{Distribusi Prior Data Jumlah Pelayanan}

Berdasarkan penelitian sebelumnya, data jumlah pelayanan berdistribusi poisson, sehingga perhitungan distribusi priornya adalah:

$$
\begin{array}{rlrl}
I(\lambda) & =-E\left[\frac{\partial^{2} \log f(y ; \lambda)}{\partial \lambda^{2}}\right] & f(\lambda) & =\sqrt{I(\lambda)} \\
& =-E\left[-\frac{y}{\lambda^{2}}\right] & & =\frac{1}{\sqrt{\lambda}} \\
& =\frac{1}{\lambda^{2}} E[y] & & =\lambda^{-\frac{1}{2}} \\
& =\frac{1}{\lambda^{2}} \lambda & & \propto \lambda^{-\frac{1}{2}} \\
& =\frac{1}{\lambda} &
\end{array}
$$

\subsubsection{Menghitung Distribusi Posterior}

\subsubsection{Distribusi Posterior Data Jumlah Kedatangan}

Distribusi posterior didapatkan dengan memerlukan fungsi likelihood dan distribusi prior yang telah didapatkan pada poin sebelumnya. Dimana perhitungan distribusi posteriornya sebagai berikut:

distribusi posterior $\propto$ likelihood $\times$ distribusi prior

$$
\begin{aligned}
f(\lambda \mid t) & =L(\lambda) \times f(\lambda) \\
& =\left(\frac{1}{\lambda}\right)^{n} \times \lambda^{-\frac{1}{2}} \\
& =\frac{1}{\lambda^{n+1 / 2}} \quad \sim \text { Uniform Diskrit }\left(\lambda^{n+1 / 2}\right)
\end{aligned}
$$

dengan parameter $\lambda^{n+1 / 2}=1,14470 \times 10^{28}$.

\subsubsection{Distribusi Posterior Data Jumlah Pelayanan}

Distribusi posterior didapatkan dengan memerlukan fungsi likelihood dan distribusi prior yang telah didapatkan pada poin sebelumnya. Dimana perhitungan distribusi posteriornya sebagai berikut:

distribusi posterior $\propto$ likelihood $\times$ distribusi prior

$f(\lambda \mid t)=L(\lambda) \times f(\lambda)$ 


$$
\begin{aligned}
& =\left(\frac{1}{n}\right)^{n} \times \lambda^{-\frac{1}{2}} \\
& =\frac{\lambda^{-\frac{1}{2}} \times e^{-\lambda n} \lambda^{\sum_{i=1}^{n} y_{i}}}{\prod_{i=1}^{n} y_{i} !} \\
& =\frac{e^{-\lambda n} \times \lambda^{2 x-\frac{1}{2}}}{\prod_{i=1}^{n} y_{i} !} \sim \operatorname{Gamma}\left(\frac{1}{n}, \sum_{i=1}^{n} y_{i}+\frac{1}{2}\right)
\end{aligned}
$$

dengan parameter $\frac{\mathbf{1}}{n}=0,02857$ dan $\sum_{i=1}^{n} y_{i}+\frac{1}{2}=216,5$.

\subsection{Model Sistem Antrean}

Berdasarkan hasil analisis steady-state serta distribusi posterior dari data jumlah kedatangan dan jumlah pelayanan di Stasiun Semarang Tawang dapat ditentukan bahwa

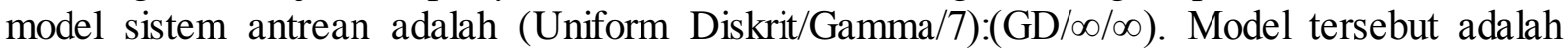
model sistem antrean dengan jumlah kereta api yang datang berdistribusi uniform diskrit dan jumlah kereta api yang dilayani berdistribusi gamma, dengan jumlah sistem pelayanan sebanyak 7 jalur kereta, disiplin antrean yang digunakan adalah FCFS, jumlah kapasitas pelanggan yang datang dan sumber pemanggilan tak terbatas.

\subsection{Ukuran Kine rja Sistem}

Ukuran-ukuran kinerja sistem antrean kereta api di Stasiun Semarang Tawang dengan interval waktu 120 menit adalah sebagai berikut

Tabel 2. Ukuran Kinerja Sis tem Stasiun Semarang Tawang

\begin{tabular}{cccccccc}
\hline $\mathrm{c}$ & $\lambda$ & $\mu$ & $\boldsymbol{L}_{\boldsymbol{q}}$ & $\boldsymbol{L}_{\boldsymbol{s}}$ & $\boldsymbol{W}_{\boldsymbol{q}}$ & $\boldsymbol{W}_{\boldsymbol{s}}$ & $\boldsymbol{P}_{\mathbf{0}}$ \\
\hline $\mathbf{7}$ & 6,17143 & 6,17143 & 0,000000373 & 1,000000373 & 0,0000000604 & 0,16204 & 0,36788 \\
\hline
\end{tabular}

\section{KESIMPULAN}

Kesimpulan yang diperoleh dari hasil analisis dan pembahasan pada penelitian ini yaitu sistem pelayanan kereta api Stasiun Semarang Tawang dengan perhitungan interval 120 menit didapatkan hasil bahwa distribusi posterior dari jumlah kedatangan kereta api adalah distribusi uniform diskrit dan distribusi posterior dari jumlah pelayanan kereta api adalah distribusi gamma. Berdasarkan hasil distribusi posterior untuk data jumlah kedatangan dan jumlah pelayanan tersebut, maka model antrean yang menggambarkan Stasiun Semarang Tawang adalah (Uniform Diskrit/Gamma/7): (GD/ $/ \infty)$ ). Sistem pelayanan kereta di Stasiun Semarang Tawang juga dapat dikatakan sudah baik berdasarkan nilai ukuran kinerja sistem yang didapatkan.

\section{DAFTAR PUSTAKA}

Aminudin. (2005). Prinsip-Prinsip Riset Operasi. Jakarta: Erlangga.

Bain, L. J. dan Engelhardt, M. (1992). Introduction Probability and Mathematical Statistics Second Edition. California: Duxburry Press.

Berger, J. O. (1980). Statistical Decision Theory and Bayesian Analysis Second Edition. New York: Springel-Verlag.

Box, G. E. P. dan Tiao, G.C. (1973). Bayesian Inference In Statistical Analysis. Philippines: Addision-Wesley Publishing Company. 
C. Armero, M. J. (1997). A Bayesian Analysis of a Queueing System with Unlimited Dervice. Journal of Statistical Planning and Inference, 241-261.

Daniel, W. W. (1989). Statistik Nonparametrik Terapan (Terjemahan). Jakarta: PT Gramedia.

Gross, D. dan Harris, C. (1998). Fundamental of Queueing Theory Third Edition. New York: John Willey and Sons.

Kakiay, T. J. (2004). Dasar Teori Antrian untuk Kehidupan Nyata. Yogyakarta: Andi.

Siagian, P. (2007). Penelitian Operasional : Teori dan Praktek. Jakarta: Universitas Indonesia Press.

Soejati, Z. dan Soebanar. (1988). Inferensi Bayesian. Jakarta: Karunika.

Subagyo, P. Asri, M. dan Handoko, T. H. (1992). Dasar-Dasar Operation Research. Yogyakarta: BPFE. 